\title{
The need for change of the transport mode in the great cities of Romania
}

\author{
I. Străinescu \& V. Rădulescu \\ $R \& D$ Department, ICPE SAERP, Bucharest, Romania
}

\begin{abstract}
The development of the great cities in Romania, especially of the capital, Bucharest, and the dramatic rise in the number of cars, most of them purchased from Western Europe, has, over a long period of usage contributed to the pollution of these cities and resulted in horrific urban traffic, particularly during the morning and evening rush hours.

To provide alternative transportation in Bucharest and the surrounding areas, RATB uses $300 \mathrm{~km}$ of tram lines with a park of 500 tram wagons, 18 trolley lines with a $485 \mathrm{~km}$ network and a park of 300 trolleys, the bus transport system with a $2900 \mathrm{~km}$ network and a park of 1300 buses, 3 Light Rail - LR lines and 4 subway lines. During rush hours, the tram and trolley lines are most of the time obstructed by cars, so the average transport speed is $6-9 \mathrm{~km} / \mathrm{h}$ for trolleys and $8-10 \mathrm{~km} / \mathrm{h}$ for trams.

The traffic travel time for cars is around 220,000 vehicles/hour, 18,000 vehicles/hour for cabs and 854,000 passengers/hour for urban transportation with electrical vehicles and buses.

The impact on the environment can be measured in noise levels which for 2007 were estimated at $62.8 \mathrm{~dB}$ and polluting car emission level: $2 \mathrm{t} \mathrm{NO}_{\mathrm{X}}, 10 \mathrm{t}$ $\mathrm{CO}, 1.2 \mathrm{t}$ unburned hydrocarbon / particles, $357 \mathrm{t} \mathrm{SO}_{2}, 1113 \mathrm{t} \mathrm{CO}_{2}$.

This paper will examine the decision factors and the planning concerns to provide a more efficient urban transport in Bucharest and other great cities in Romania, especially with electrical vehicles. To this end the paper proposes a methodology to optimize the selection mode and the track design for Light Rail LR, using existing tram lines with the necessary additions, the construction of new subway lines for the busy areas and the continuous development of the tram and trolley urban transportation.

Keywords: transit modes, mode selection, transit decision, capacity, travel time, light rail-LR, Metro, trams.
\end{abstract}




\section{Introduction}

To ensure this kind of transportation in Bucharest and surroundings, RATB uses a network of $60 \mathrm{~km}$ with 3 Light Rail - LR, over $300 \mathrm{~km}$ tramcar lines with a park of almost 500 tramcars, 18 trolley bus lines with a park of 300 trolley buses and a bus park of 1300 [3]. The transportation lines in Bucharest also depend on the 4 subway lines so that the transportation is improved.

During rush hours, the tram and trolley lines are most of the time obstructed by cars so the average transport speed is $8-10 \mathrm{~km} / \mathrm{h}$ for trams and $6-9 \mathrm{~km} / \mathrm{h}$ for trolley buses, and during the rest of day there are 10-14 km/h for trams and 9-14 $\mathrm{km} / \mathrm{h}$ for trolley buses, fig. 1 .

Today the gases produced by automobiles and some abuses pollute Bucharest intensely and this happens also due to the few regulations in our country that allow the running of cars and buses, which emanate large quantities of polluting emissions well over the level allowed in Western Europe [4].

Although the public authorities from Bucharest, Cluj-Napoca and Iasi have approved a massive introduction in public transportation of the electric transport means (non-polluting transport), the traffic in the rush hours is terrible because of massive car traffic.

In order to significantly improve the traffic in the big cities, especially in the capital Bucharest, there are several improvement proposals, which can produce higher traffic fluency without massive investments.

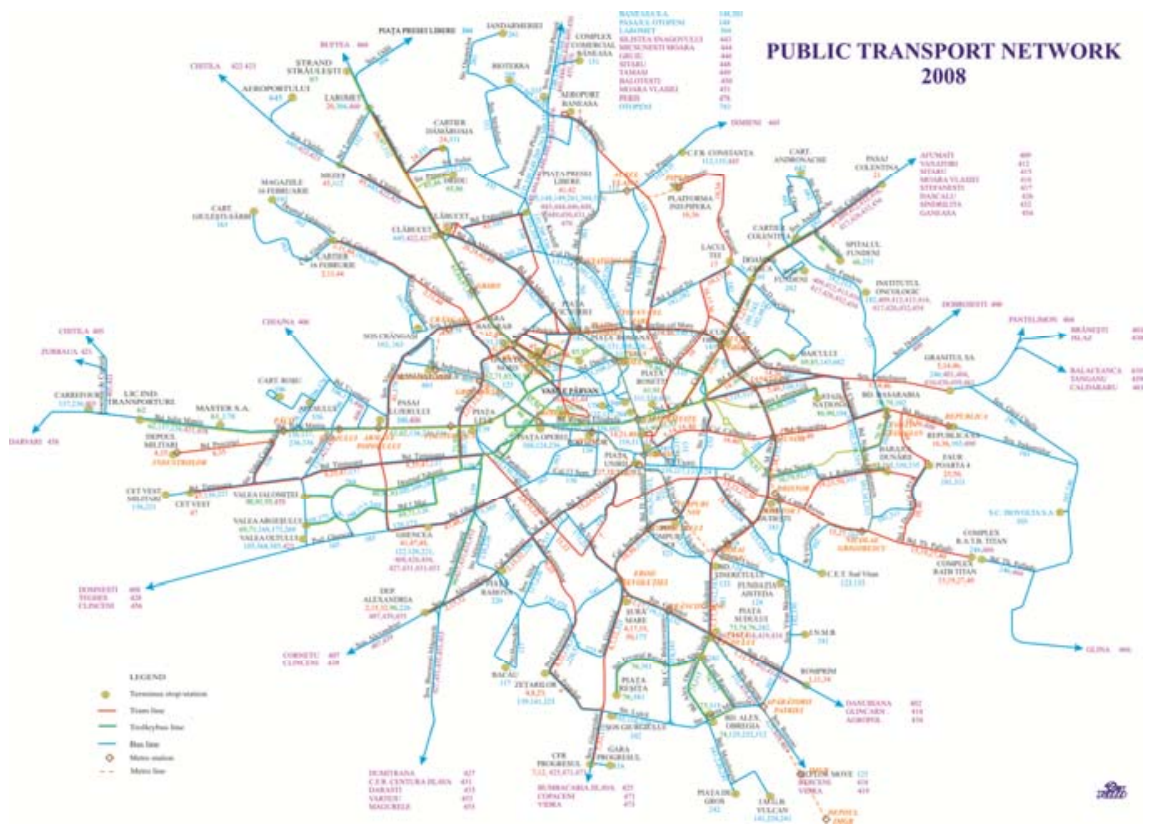

Figure 1: The urban transport network in Bucharest. 


\section{Major measures needed to change the transport mode}

From the environmental point of view, it is obvious that urban transportation has to be based on subway frames transport lines, Light Metro - LM (special tramcar lines) that will ensure free run (with automated barriers that will interrupt the run of other vehicles when LM passes), ordinary tramcar and trolley bus lines, electric bus, electric trains, suspended electrical vehicles, dynamic electrical sidewalks and so on.

Various cities and metropolises try to resolve the issue of making urban transportation more efficient with a lower pollution level. Cities that can ensure an efficient non-polluting public transportation, indirectly assure the reduction of pollution from the cars, because of the share reduction from public transportation assurance.

According to the PMB Master Plan [3], elaborated by Bucharest City hall for the period 2008-2027, the next step is to increase the capacity of the road transportation network in Bucharest.

An important measure from this plan is the construction of a railway belt that would unite the seven railway stations through a double line. This would ensure at least 4-6 electric railway trains per hour every way on this double line and it wishes to reduce transport by car in Bucharest, fig. 2.

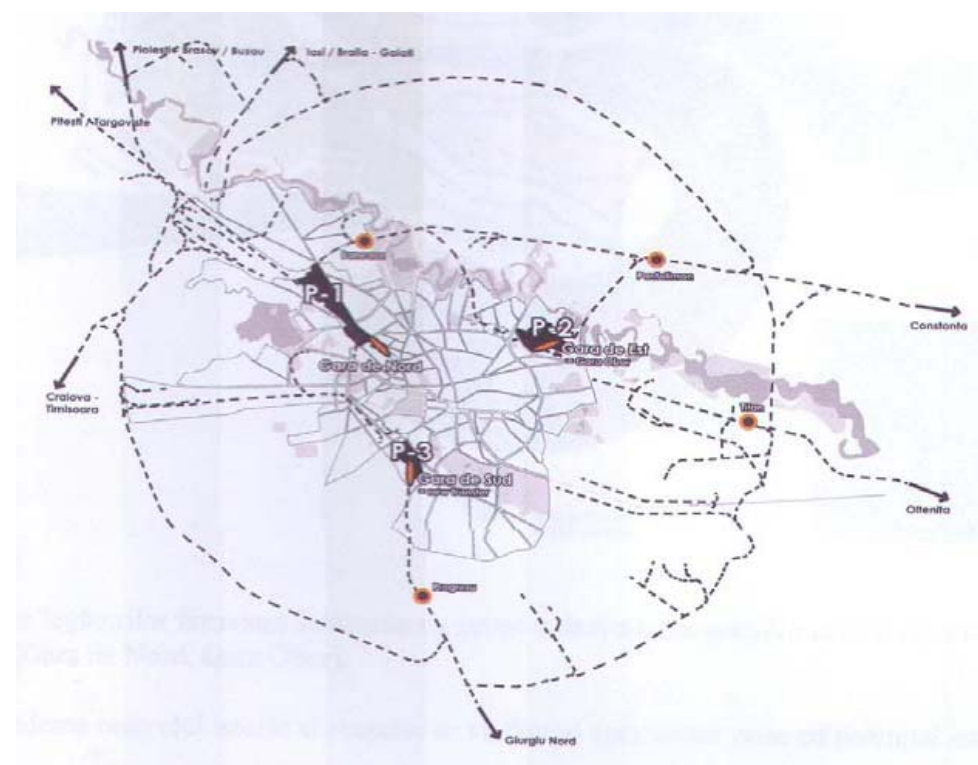

Figure 2: The future railway outer beltline of Bucharest. Notes: P-1, P-2 and $\mathrm{P}-3$, the main train stations for the beltline and the railway network that should be used partly and then entirely between 2015 and 2020 . 
This transport mode will connect all the sectors of Bucharest through the railway outer beltline, especially the ones farthest from the centre of the city. It will also connect with the commuter trains from around Bucharest.

The present railway network has not been used for roughly 10 years, even over 20 years in some parts. The rail track must be modernised, equipped with an electrical supply line of $25 \mathrm{kV}-50 \mathrm{~Hz}$ or a $3 \mathrm{kVdc}$ line, to supply the electrical frames. The existing train stations P-1, P-2, P-3 must also be modernised and in addition four more modern stations, with minimum or no personnel must be built. The necessary electrical frame park will be assimilated and completed within the country.

To design the urban electrical transport mode in Bucharest, a few criteria were taken into consideration: the system capacity, travel time, comfort /accessibility, on-time performance and, most importantly, the investment amount, depending on the particularity of the transport in the great cities in Romania, especially Bucharest.

Concerning the comfort/accessibility issue, these attributes refer to the relative comfort of passengers. This attributes include stop and vehicle amenities (controlled temperature inside vehicle, transport quality, type of seating, access to information, easiness of fare payment, access, security, cleanliness, etc) [4].

Fig. 3 presents the speed ranges for the urban electrical transport in Bucharest under normal exploitation conditions (in the morning between 5 and $7 ; 21$ and 24; average and maximum speed value between 10 and 15); fig. 4 presents rush hours values (7-10, respectively 15-21).

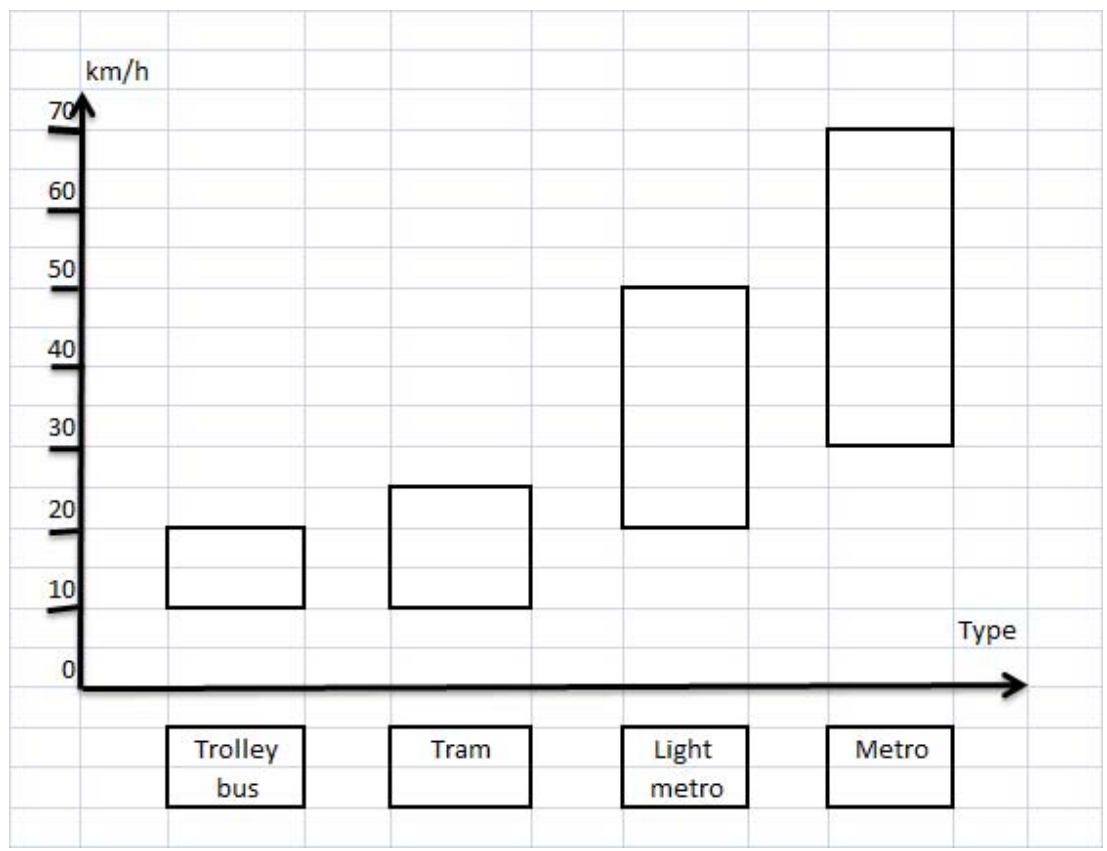

Figure 3: Average speed under normal exploitation conditions. 


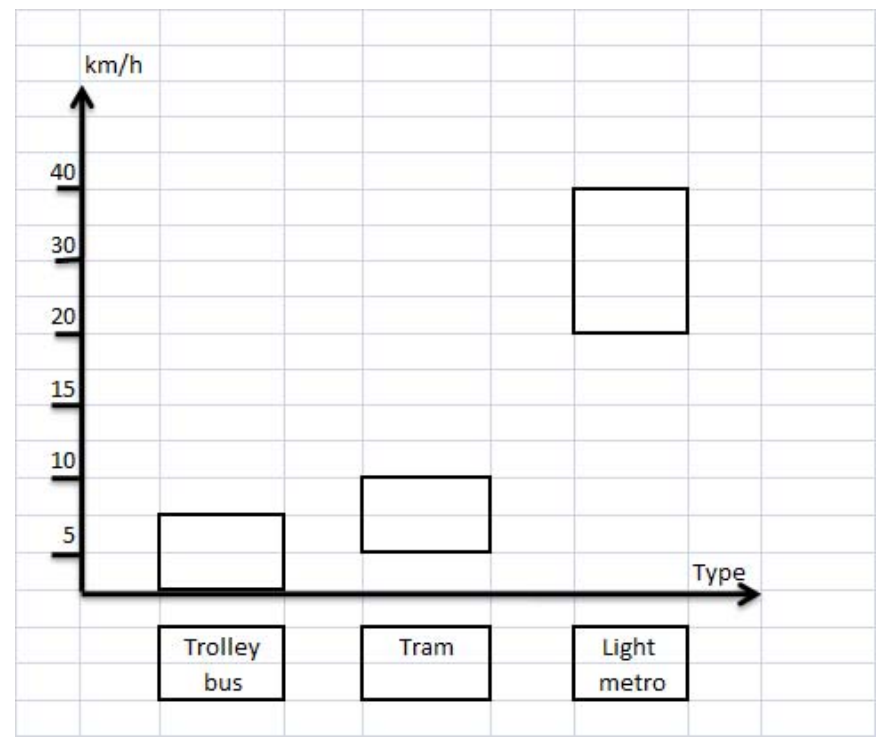

Figure 4: Average speed during rush hour conditions.

For conclusive results, we will next analyze the four main electrical urban means of transport - metro, light metro, tram and trolley bus - to obtain the necessary data for planning the next 2-5 years and, respectively, the next 10 years.

\subsection{Metro}

Presently there are 5 metro lines as can be observed from fig. 5. These ensure an efficient transport in the centre of the city and a few other areas. The average distance between stations is between 800 and $1000 \mathrm{~m}$ in the city centre and 1000 to $1500 \mathrm{~m}$ in the other areas.

For the next period a new subway line project has been launched. This would travel Bucharest from west to east, transporting passengers from Drumul Taberii to Pantelimon, two areas that are presently suffocated by the large numbers of automobiles. Another line will connect the Northern part of the city to the H. Coanda International Airport.

\subsection{The light metro transport development}

Light metro (or light rail) has to be understood along the UTP definition, i.e.: "a tracked, electrically driven local means of transport, which can be developed step by step from a modern tramway to a means of transport running in tunnels or above ground level. Every development stage can be a final stage in itself. It should however permit further development to the next higher stage" [4]. 


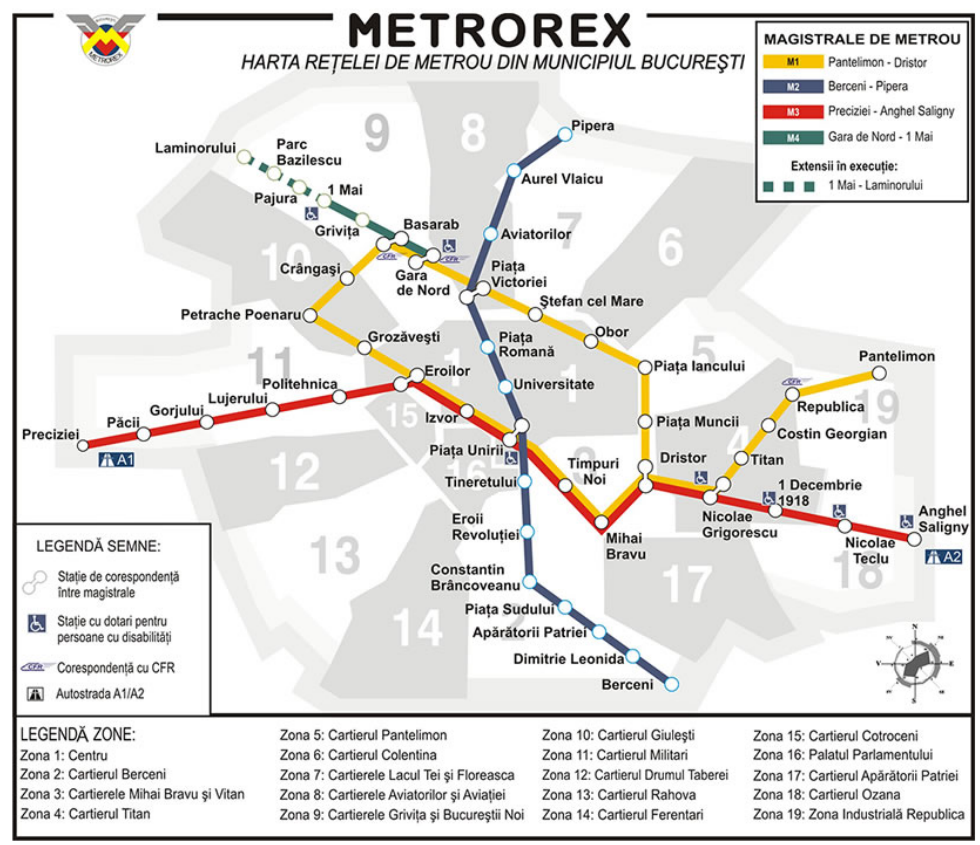

Figure 5: $\quad$ The metro network in Bucharest.

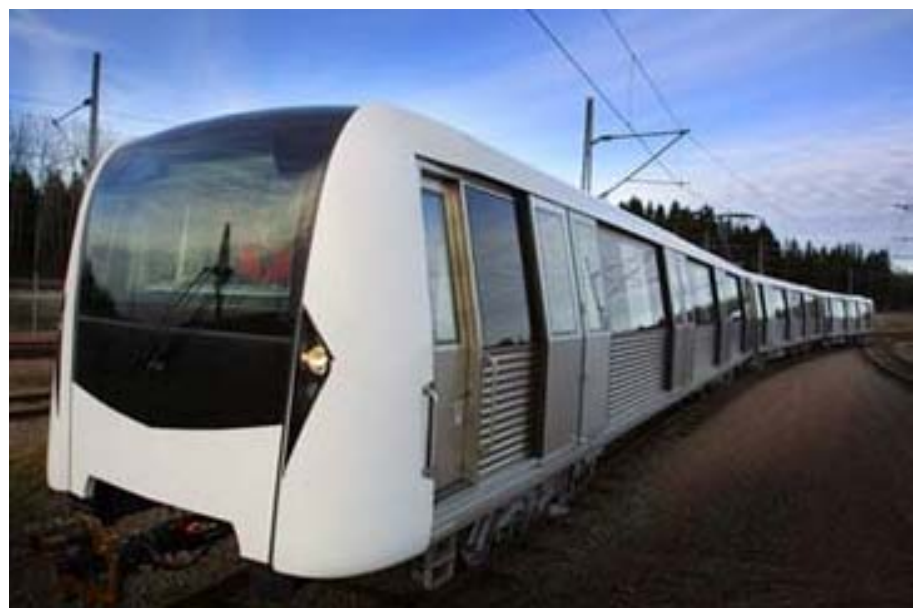

Figure 6: Metro frame used on the Berceni - Piata Unirii - Piata VictorieiPipera line.

As can be observed from fig. 4 the light metro - LM has an average speed (including stops) of more than $40 \mathrm{~km} / \mathrm{h}$ even during rush hour. These results are from the RATB reports concerning the $41 \mathrm{LM}$ line, in exploitation for 4 years in Bucharest. 
Classical trams without multiple train command run on this LM line, but the passengers and specialists consider it a great achievement because over $85 \%$ of the track is closed to other transport vehicles and automobiles.

The development of the LM transport on the 41 line with a length of $18 \mathrm{~km}$ the following will be necessary:

- The purchase of electrical trains made of 2 or 3 tram motors with hierarchical command on at least 3 levels: command on the length of the train, wagon command and the bogie command.

- Ensuring an at least $95 \%$ protected track, with modern stations - long enough for three electrical frames.

- Ensuring automatic barriers in main intersections that would go down when the LM passes.

Starting from experience to achievement with the $41 \mathrm{LM}$ line, for the next 5 years we propose the transformation of existing tram lines 8, 35, 11 and 5 in LM lines, for which the above mentioned requirements for the modernising of line 41 must be followed step by step.

On the interior ring will be required 2 way Light Metro, but for this must fulfil a list of conditions including the protection of the route against the crossing cars.

In this way, the LM line length would have reached $100 \mathrm{~km}$ by the year 2015 . In another 5 years, 5 more tram lines, from the existing 18, could be transformed in LM transport lines.

\subsection{Modernising the tram transport}

The present tram lines cover the main transport areas from Bucharest, but there is always need for new lines, according to the feasibility calculations. The most important issue is the modernisation of the existing park of 500 trams; after taking into account their usage, at least 200 trams can be modernised.

The purchase of about 250 new trams will be necessary. The modernisation started through the collaboration between RATC and ICPE SAERP Bucharest, i.e. modernising three trams in 2010; 15 more trams are planned to be modernised in 2011. Fig. 7 presents the modernised trams.

\subsection{Development of the trolley bus transport}

As specified in the Bucharest Transport Master Plan [3], trolley bus transport will be especially developed on the central tracks in Bucharest, where there are no tram or LM lines. Taking into account the numbers presented in fig. 4 regarding rush hour average speed, the urban electrical transport will not improve if additional measures are not implemented to restrict automobile traffic in the central areas during rush hour (such as a mandatory entrance fee to the central areas).

The existing 300 trolleys are sufficient: they are chopper driven and have a direct current motor or a three phase inverter and asynchronous traction motor, some of them have a lowered floor, fig. 8. But we have to take into account that 


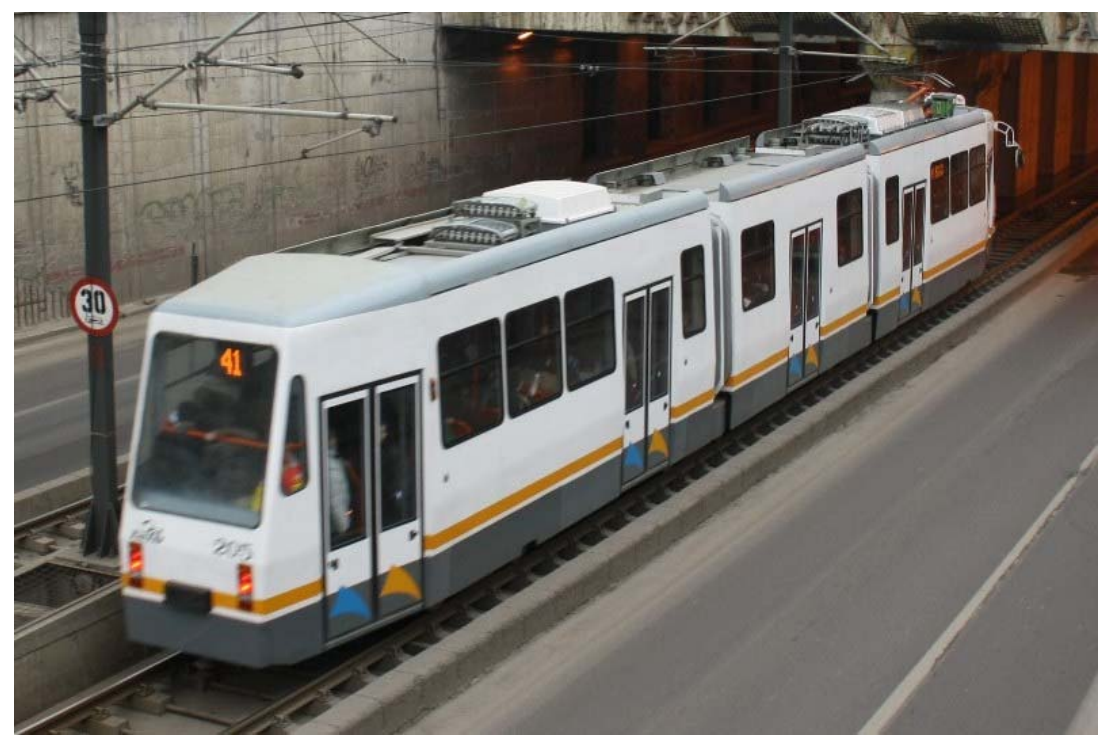

Figure 7: $\quad$ RATB - ICPE SAERP modernised tram.

the normal operating time is of 7 years, they will soon have to be replaced with new modern ones.

\section{Conclusions}

From the analysis done by various authorities in Europe, Japan and the USA we reached the conclusion that the pollution in the big cities may be reduced if a well organized urban transportation system can be assured, with modern means of transportation, especially those that use underground and surface subway networks (on special routes, including light-metro - LM), completed by connection lines that use tramcars, trolley buses and hybrid fuel cell based electrical buses that have also a parallel connection for supplying the traction system from modern electrical storage batteries.

In addition to this, through a well-organized urban electric transportation, we can assure an optimum run of passengers from the big cities, with an acceptable comfort and drastic limitation of pedestrian and bicycle related accidents.

The paper strongly recommends the extension of the light metro lines -LM in Bucharest, using part of the existing tram tracks, modernising the track and station infrastructure, blocking the automobile access to the LM tracks, by modernising the traffic lights and introducing automatic barriers and electrical frames with hierarchical command on at least three levels.

All of this implies large investments distributed on long time periods and respectively subsidies from the city halls that should cover the exploitation costs after renouncing of most of the diesel buses and powerful expansion of nonpolluting electrical transportation. 


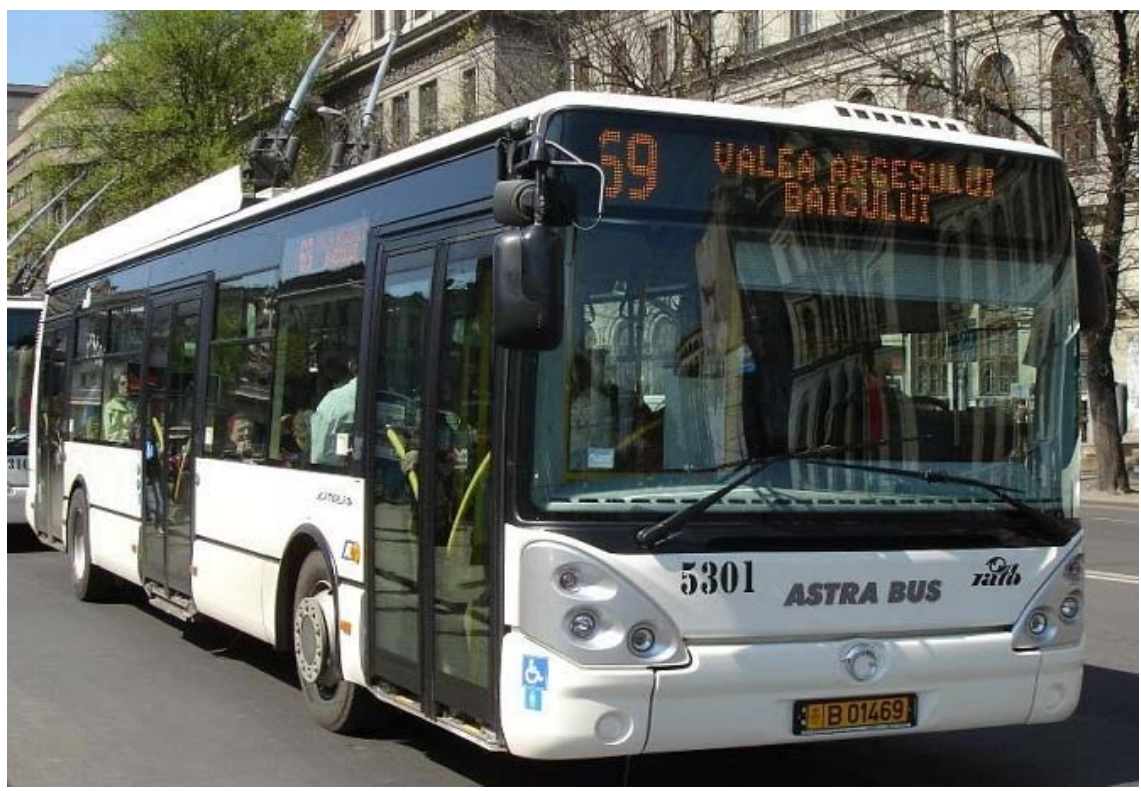

Figure 8: $\quad$ ASTRA BUS - ICPE SAERP trolleybus in Bucharest.

According to the Master Plan PMB, elaborated by the Bucharest City hall for the 2008-2027 period, it is to be followed that the capacity of urban transportation network will increase.

The improvement of the public transportation will be done not only by introducing new routes/lines, but also by improving the performances of existing networks and also by implementing intelligent traffic management systems.

\section{References}

[1] Green Paper. Towards a new culture for urban mobility. Commission of the European Communities. Brussels, 25.9. 2007- COM (2007) 551 FINAL.

[2] EEA Report Transport at cross roads - 2009 TERM 2008: Indicators tracking transport and environment in the European Union

[3] Master Plan for Urban Transport in Bucharest. 15.04.2008, General Counsel of Bucharest.

[4] Hubell J., Wirasinghe S.C., McKendrick N., Morgan D., Mode succession in a public transit corridor, Urban Transport XV -2009, WIT Press.

[5] Light Rail and Metro Systems in Europe. Current market, Perspectives and research implication. ERRAC the European Rail Research Advisory Council, 2004. 